\title{
Chronic infusion of nitric oxide in experimental pulmonary hypertension: pulmonary pressure-flow analysis
}

\author{
V. Hampl*, M. Tristani-Firouzi**, D.P. Nelson*, S.L. Archer*
}

Chronic infusion of nitric oxide in experimental pulmonary hypertension: pulmonary pressure-flow analysis. V. Hampl, M. Tristani-Firouzi, D.P. Nelson, S.L. Archer. (CERS Journals Ltd 1996.

ABSTRACT: Inhaled-nitric oxide (NO) is a selective pulmonary vasodilator in shortterm clinical studies. Use of NO inhalation in chronic pulmonary hypertension is complicated by potential problems with ambulatory NO delivery. We hypothesized that long-term infusion of NO solution into the central venous circulation, which did not suffer from this drawback, might reduce chronic pulmonary hypertension.

Saturated NO solution was infused in chronically hypoxic rats by implantable minipumps at a rate which was effective in reducing acute hypoxic vasoconstriction in isolated, Krebs' albumin perfused lungs $\left(2.5 \mathrm{\mu L} \cdot \mathrm{h}^{-1}\right)$. Pulmonary haemodynamics and the pressure-flow relationship were studied after 4 weeks of infusion.

NO was still present in the minipumps at the end of the infusion period. Despite causing methaemoglobinaemia, NO infusion did not significantly attenuate pulmonary arterial pressure, pulmonary vascular resistance, right ventricular hypertrophy, or the parameters of the pulmonary vascular pressure-flow relationship. Pressure-flow curves, analysed with the nonlinear, distensible vessel model, indicated increased near-zero pressure resistance $\left(R_{0}\right)$ in chronic hypoxia. The tendency of chronic NO infusion to reduce $R$ o did not reach statistical significance.

Long-term infusion of nitric oxide solution is technically feasible but does not effectively reverse chronic pulmonary hypertension. The failure of infused NO to reduce pulmonary hypertension is explained by the fact that the inactivation of NO by haemoglobin is much faster than anticipated.

Eur Respir J., 1996, 9, 1475-1481.

Pulmonary hypertension is a leading cause of morbidity and mortality in association with chronic obstructive pulmonary disease (COPD), adult respiratory distress syndrome (ARDS), or congenital heart disease, and as a primary disorder [1]. Nitric oxide (NO) is a potent pulmonary vasodilator [2-4]. When inhaled, NO selectively dilates the pulmonary vasculature $[3,4]$. In situations requiring acute and subacute treatment, such as neonatal pulmonary hypertensive crisis or ARDS, inhaled NO is highly effective in reducing pulmonary hypertension [5-8]. In these situations, the patient is typically intubated and continuously attended by specially trained medical staff, and the duration of the treatment is relatively short. The usefulness of inhaled NO in chronic diseases, such as COPD, has not been systematically clinically tested, partly due to fears of NO toxicity, and particularly due to technical difficulties related to the ambulatory delivery of inhaled NO gas. Nevertheless, the ability of long-term NO inhalation to reduce chronic hypoxic pulmonary hypertension and related right ventricular hypertrophy has been demonstrated in adult and neonatal rats $[9,10]$.

Chronic NO inhalation in humans would require very strict safety precautions. The patients would probably have to carry tanks with NO gas mixed with an inert gas. NO cannot be added to tanks containing a high concentration of oxygen because NO is inactivated by reaction with oxygen, yielding highly toxic nitrogen dioxide
Depts of *Medicine and **Pediatrics, University of Minnesota and VA Medical Center, Minneapolis, MN, USA.

Correspondence: S.L. Archer Cardiovascular Section (111C) VA Medical Center One Veterans Drive

Minneapolis MN 55417 USA

Keywords: Implantable osmotic minipumps isolated perfused rat lung pressure-flow curves pulmonary vascular resistance

Received: May 291995

Accepted after revision January 141996

The study was supported by the American Heart Association-Minnesota Affiliate GrantIn-Aid, US Department of Veterans Affairs, Minnesota Medical Foundation, and the National Institutes of Health Grant \#1R29HL45735.
$\left(\mathrm{NO}_{2}\right)$. This reaction is very fast unless the concentrations of $\mathrm{NO}$ and $\mathrm{O}_{2}$ are very low [11]. The NO concentration in a tank would have to be quite high, or the amount of inert gas required to carry a sufficient amount of NO into the airways would be large enough to significantly reduce the inspiratory oxygen fraction $\left(F \mathrm{I}, \mathrm{O}_{2}\right)$. Tanks with high concentrations of $\mathrm{NO}$ are potentially dangerous, because a leak could result in the ambient NO concentration exceeding the US Occupational Safety and Health Administration limit of 25 parts per million (ppm). More importantly, NO leaking into the room air would be rapidly oxidized to $\mathrm{NO}_{2}$, which causes severe lung injury after inhaling $50 \mathrm{ppm} \mathrm{NO}_{2}$ for only 5 min [12]. For these reasons, practical implementation of longterm inhalational NO therapy is difficult. We speculated that an alternative means of NO administration, namely intravenous infusion, would not suffer from this drawback.

The potential advantage of intravenous NO infusion using an implantable pump and right atrial cannula is that NO would enter the bloodstream close to the beginning of the pulmonary artery. As a result, the travel time to the desired site of action, pulmonary arterioles, is short. By contrast, the travel time to the systemic arterioles (where NO would produce systemic hypotension), is much longer. Since NO is rapidly inactivated by haemoglobin and oxidized to nitrite $\left(\mathrm{NO}_{2}^{-}\right)$and nitrate $\left(\mathrm{NO}_{3}^{-}\right)$, little should survive to reach the systemic circulation [13]. 
It was hypothesized that the NO infusion would allow a sufficient amount of NO to survive in the haemoglobinrich environment of the blood for long enough to reach the pulmonary circulation, but not long enough to reach the systemic arteries. The pulmonary and systemic effects would, thus, be maximized and minimized, respectively. The long-term infusion of saturated NO solution was tested in rats with pulmonary hypertension elicited by chronic hypobaric hypoxic exposure. In order to characterize, in detail, the effects both of chronic hypoxia and long-term NO infusion, the pulmonary perfusionpressure flow relationship was also studied using the recently developed version of a nonlinear, distensible vessel model [14].

\section{Methods}

\section{Study design}

Implantable osmotic minipumps were used to infuse saturated NO solution throughout the entire study (4 weeks). The study duration dictated the NO infusion rate, as the only commercially available minipump for rats capable of infusing for more than 1 week infuses at $\sim 2.5$ $\mu \mathrm{L} \cdot \mathrm{h}^{-1}$. To see whether saturated NO solution possesses pulmonary vasodilator activity even at this low infusion rate, the effect of this NO infusion regimen was first measured on acute hypoxic vasoconstriction in isolated lungs of control rats perfused with Krebs' albumin solution. When a clear vasodilatory effect had been observed, the minipumps were implanted in a group of rats subsequently exposed to chronic hypoxia in order to elicit pulmonary hypertension. Four weeks later, in vivo pulmonary haemodynamics were studied in thoracotomized rats, and compared to groups without NO infusion (chronic hypoxic and normoxic). Pulmonary vascular pressureflow $\left(P / Q^{\prime}\right)$ properties were measured using isolated perfused lung preparations. The study was approved by the Minneapolis VA Medical Center Animal Studies Subcommittee and University of Minnesota Animal Care Committee.

\section{Acute slow NO infusion}

Four experiments were performed using the isolated, Krebs' albumin perfused lung model described below. The lungs of normal, control rats were challenged with hypoxia $\left(2.5 \% \mathrm{O}_{2}\right.$ in inhaled gas for $6 \mathrm{~min}$; both normoxic and hypoxic gas mixture contained $5 \% \mathrm{CO}_{2}$ ) after being pretreated with angiotensin II injection $(0.15 \mu \mathrm{g})$ into the inflow line $8 \mathrm{~min}$ earlier [15]. Angiotensin II caused a transient vasoconstriction followed by a return to preinjection pressure within 2 min (fig. 1). The angiotensin II hypoxia cycles were repeated at $10 \mathrm{~min}$ intervals five more times. After the third hypoxic challenge (when the magnitude of the response had stabilized [16]), infusion of saturated NO solution at $2.5 \mu \mathrm{L} \cdot \mathrm{h}^{-1}$ was begun (using a Harvard syringe pump) and was continued throughout the rest of the protocol in half of the experiments (fig. 1). Oxygen tension $\left(\mathrm{PO}_{2}\right)$ of the lung effluent

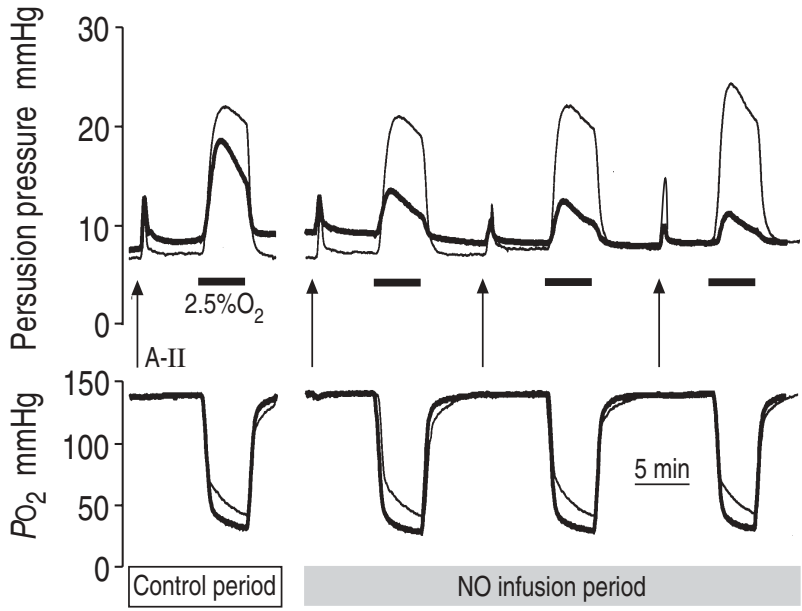

Fig. 1. - Acute slow infusion of saturated nitric oxide (NO) solution reduces vasoconstrictor reactivity in isolated perfused rat lungs. Each point of each trace is a mean of two preparations. NO infusion at 2.5 $\mu \mathrm{L} \cdot \mathrm{h}^{-1}$ reduces both hypoxic and angiotensin II (A-II)-induced pulmonary vasoconstriction, as compared both to the period before the infusion in the same lung and to the relevant periods in lungs that did not received the infusion. There were no differences in oxygenation to account for the differences in vasoreactivity (on-line effluent $\left(\mathrm{PO}_{2}\right)$ is shown at the bottom).

was measured continuously by means of a flow-through dissolved oxygen electrode (DO-166FT, Lazar Research Laboratories, Los Angeles, CA, USA) inserted into the perfusion circuit $\sim 8 \mathrm{~cm}$ downstream from the lung outflow cannula.

Additional experiments were performed using the same protocol but with lungs perfused with blood (containing $17 \mu \mathrm{M}$ meclofenamate) [17]. Blood for perfusion of one lung $(\sim 15-20 \mathrm{~mL})$ was obtained from three pentobarbital-anaesthetized $\left(50 \mathrm{mg} \cdot \mathrm{kg}^{-1}\right.$ i.p. $)$ donor rats by cardiac puncture. The perfusion circuit contained a transfusion filter (SQ40S; Pall Biomedical, Fajardo, Puerto Rico). In the blood-perfused lungs the "priming" with angiotensin II before each hypoxic challenge was not necessary to obtain large vasopressor responses and was, therefore, omitted (only one angiotensin II bolus $(0.15 \mu \mathrm{g})$ was given at the beginning of the perfusion). Three lungs received NO infusion and two lungs served as controls (infused with deoxygenated saline only).

\section{Experimental groups}

For the main study with chronic NO infusion, male, specific pathogen-free Sprague-Dawley rats (Harlan, Madison, WI, USA) were divided into three groups: normoxic control, chronic hypoxic $(\mathrm{CH})$; and chronic hypoxic receiving $\mathrm{NO}$ infusion $(\mathrm{CH}+\mathrm{NO})(\mathrm{n}=6$ in each group).

\section{Preparation of $\mathrm{NO}$ solution}

Saturated NO solution $(\sim 2 \mathrm{mM})$ was prepared as follows: distilled water was deoxygenated with $\mathrm{N}_{2}$, bubbled with $100 \%$ NO gas (Matheson, Chicago, IL, USA) for $20 \mathrm{~min}$, and then stored in a glass airtight container [18]. The osmotic minipumps were filled with saturated NO solution under sterile conditions using $\mathrm{N}_{2}$-flushed syringes. The NO filled pumps were bathed in $37^{\circ} \mathrm{C}$ warm, deoxygenated saline for at least $4 \mathrm{~h}$ prior to implantation. 


\section{Pump implantation}

Three days before the start of the hypoxic exposure, NO treated rats were implanted with Alzet osmotic minipumps (model 2ML4; Alza Corp., Palo Alto, CA, USA) that continuously infused saturated NO solution into the central venous circulation. NO solution $(2 \mathrm{mM})$ was infused at a rate of $2.5 \mu \mathrm{L} \cdot \mathrm{h}^{-1}$ for 4 weeks. The $\mathrm{CH}$ rats received no infusion, but two of them underwent the surgery to implant an empty osmotic minipump as a sham control. The results obtained from these two rats did not differ from other $\mathrm{CH}$ rats (who did not undergo any surgery). Therefore, the data from $\mathrm{CH}$ rats that did and did not have the sham surgery were pooled.

For pump implantation, the rats were anaesthetized with pentobarbital sodium $\left(50 \mathrm{mg} \cdot \mathrm{kg}^{-1}\right.$ i.p. $)$. In addition, local anaesthesia was applied to the throat area (0.3-0.4 $\mathrm{mL}$ of $2 \%$ lidocaine). Using an aseptic technique, the right internal jugular vein was exposed and cannulated with PE-60 polyethylene tubing attached to an osmotic minipump. Care was taken to advance the tip of the cannula close to or into the right atrium. The pump was then tunnelled subcutaneously into the midscapular area. The rats were allowed to recover for 3 days before exposure to chronic hypoxia. During this time, they received 2 $\mathrm{mg} \cdot \mathrm{mL}^{-1}$ acetaminophen in their drinking water to control postoperative pain. They were watched throughout the study period for signs of wound infection or bleeding, but no problems were encountered.

\section{Pulmonary hypertension}

Chronic hypoxic rats were exposed to hypobaric hypoxia for 4 weeks, as described previously [19]. The pressure in the chamber was decreased progressively from 0.8 atm on Day 1 to 0.45 atm after Day 6 , and was maintained at $0.45 \mathrm{~atm}$ thereafter. The chamber was opened once every 2-3 days for cleaning and feeding. The chamber was kept at $37^{\circ} \mathrm{C}$ and a soda lime tray was changed weekly to prevent accumulation of $\mathrm{CO}_{2}$. All rats had ad libitum access to food and water.

\section{In vivo haemodynamics}

Four weeks after initiation of hypoxia, rats were removed from the chamber and anaesthetized with pentobarbital sodium $\left(50 \mathrm{mg} \cdot \mathrm{kg}^{-1}\right.$ i.p.). They were mechanically ventilated with air through a tracheostomy at 65-75 breaths $\cdot \mathrm{min}^{-1}$. Tidal volume was $2.5-3.0 \mathrm{~mL} \cdot \mathrm{min}^{-1}$. The chest was opened in the midline. An ultrasonic flow probe (Transonic Systems, Ithaca, NY, USA) was positioned around the ascending aorta for measurement of cardiac output. Main pulmonary artery and ascending aortic pressures were measured by direct puncture with a 25-gauge needle attached to a pressure transducer. Because of the differences in body weight (BW) between groups, cardiac index was determined by dividing cardiac output by body weight. Indexed total pulmonary and systemic vascular resistances were calculated by dividing mean pulmonary and systemic arterial pressures by cardiac index. Pulmonary vascular resistance was not used because of the technical difficulty of measuring left atrial pressure in rats. However, the pulmonary vascular resistive properties are described even more completely by the pressure-flow relationship, which was performed after isolating the lungs (see below). After haemodynamic measurements, blood was withdrawn from the left ventricle for determination of methaemoglobin and complete blood counts. Methaemoglobin levels were measured using the IL482 CO-Oximeter (Curtin Matheson Scientific, Eden Prairie, MN, USA).

\section{Isolated lung model}

Following the in vivo measurements, rats were heparinized with $200 \mathrm{U}$ heparin i.v. and the lungs were isolated as described previously [19]. The pulmonary artery was cannulated through a right ventriculotomy with a double lumen perfusion cannula, allowing continuous measurement of perfusion pressure. The left atrium was drained through a large outflow cannula. The lungs were perfused with Krebs' solution containing 4\% albumin and $17 \mu \mathrm{M}$ meclofenamate, removed from the chest and suspended from a tracheal cannula in a thermostatically controlled $\left(38^{\circ} \mathrm{C}\right)$ humidified chamber. When the effluent was clear of erythrocytes, the perfusate was recirculated and its volume adjusted to $50 \mathrm{~mL}$. Flow rate, controlled by a pump, was set at $40 \mathrm{~mL} \cdot \mathrm{min}^{-1} \cdot \mathrm{kg}^{-1} \mathrm{BW}$. The respiratory cycle was 65 breaths $\cdot \mathrm{min}^{-1}$, and a positive end-expiratory pressure of $2.5 \mathrm{cmH}_{2} \mathrm{O}$ was applied. The tidal volume was kept at $2.5-3.0 \mathrm{~mL}$, resulting in a peak inspiratory pressure of $9 \mathrm{cmH}_{2} \mathrm{O}$. The inhaled gas mixture consisted of $20 \% \mathrm{O}_{2}, 5 \% \mathrm{CO}_{2}$ and $75 \% \mathrm{~N}_{2}$. The osmotic minipump was then removed from the body and its residual content $(\sim 0.2 \mathrm{~mL})$ was aspirated into a syringe and analysed for NO concentration using a chemiluminescence analyser [18].

To investigate the relationship between perfusion pressure and flow, the flow rate was reduced to $5 \mathrm{~mL} \cdot \mathrm{min}^{-1}$ for $30 \mathrm{~s}$ and then increased in $10 \mathrm{~mL} \cdot \mathrm{min}^{-1}$ steps $(30 \mathrm{~s}$ each) up to $45 \mathrm{~mL} \cdot \mathrm{min}^{-1}$. During the pressure-flow measurement, the lung ventilation was maintained at 65 breaths $\cdot \mathrm{min}^{-1}$, with a tidal volume $2.5-3.0 \mathrm{~mL}$, positive end-expiratory pressure of $2.5 \mathrm{cmH}_{2} \mathrm{O}(1.8 \mathrm{mmHg})$, and peak inspiratory pressure of $9 \mathrm{cmH}_{2} \mathrm{O}(6.6 \mathrm{mmHg})$. Lung outflow pressure was set to $-2 \mathrm{cmH}_{2} \mathrm{O}(-1.5 \mathrm{mmHg})$.

\section{Data analysis}

The data are presented as mean \pm SEM. The groups were compared statistically using the factorial analysis of variance followed by the Fisher least significant difference post-hoc test. For all statistical tests, a p value of less than 0.05 was required for significance. StatView 4.02 program for Macintosh (Abacus Concepts, Berkeley, CA, USA) was used for statistical calculations.

The $P / Q^{\prime}$ curves were compared between the groups with repeated measures analysis of variance (ANOVA). In addition, the $P / Q^{\prime}$ data were analysed and interpreted using the distensible vessel model of LineHAN and coworkers $[14,20]$. To do this, the nonlinear regression of the $P / Q^{\prime}$ data from each lung was calculated as follows: 


$$
\bar{P}_{\mathrm{a}}=\frac{\left[\left(1+\alpha P_{\mathrm{v}}\right)^{5}+5 \alpha R_{\mathrm{o}} Q^{\prime}\right]^{1 / 5}-1}{\alpha}
$$

The values entered were $\bar{P}$ a $=$ mean pressure measured at the arterial inflow end of the pulmonary circulation) and $Q^{\prime}$ (=flow rate, controlled by the pump). The parameters estimated in the iteration process of optimizing Equation (1) were: $\alpha=$ vascular distensibility; $R_{0}=$ vascular resistance at near-zero pressure; and $P$ v=effective outflow pressure. $P_{\mathrm{v}}$ was treated as one of the parameters because in that way a better fit to the data was obtained than by treating $P_{\mathrm{v}}$ as an entered value. Equation (1) was solved by minimizing the sum of squared errors (MarquardtLevenberg algorithm) using SigmaPlot for Macintosh 4.17 software (Jandel Scientific, San Rafael, CA, USA).

\section{Results}

\section{Acute slow NO infusion in Krebs' albumin perfused lungs}

During the first three hypoxic challenges, intended to stabilize vasoreactivity of the preparation [16], the vasoconstrictor responses did not differ significantly between the individual isolated lungs. After the onset of slow NO infusion, the hypoxic vasoconstrictor responses progressively diminished, whereas those in lungs not infused with NO remained stable (fig. 1). The same was true for the vasoconstrictor responses to angiotensin II, though to a less marked degree.

\section{Chronic NO infusion in pulmonary hypertension}

The technique used to implant the minipumps was successful, in that NO survived in the minipumps throughout the whole study period of 4 weeks. At the completion of the study, the concentration of NO in the pump was $0.2 \mu \mathrm{M}$. As the goal of this measurement was not a detailed analysis of the NO decomposition kinetics in the pump, no precautions were taken to prevent NO oxidation during the aspiration of the fluid from the pumps. Consequently, these data cannot support any conclusion about the rate of $\mathrm{NO}$ oxidation in the minipump, but do confirm that NO was being infused throughout the study period.

There was no mortality in any of the groups during the study period. Exposure to chronic hypoxia resulted in pulmonary hypertension. Mean pulmonary artery pressure, indexed pulmonary vascular resistance and right ventricular weight were elevated in chronic hypoxic rats compared to normoxic controls, while no significant changes were noted in cardiac index, systemic artery pressure or indexed systemic vascular resistance (table 1). Total haemoglobin and haematocrit were elevated in hypoxic rats compared to normotensive controls (table 2 ). Despite effective infusion, confirmed by the extreme methaemoglobinaemia in the $\mathrm{CH}+\mathrm{NO}$ group (table 2 ), NO infusion did not reduce pulmonary hypertension (table 1). Total haemoglobin in hypoxic rats treated with NO infusion was significantly higher than in the $\mathrm{CH}$ group
Table 1. - Haemodynamic data

\begin{tabular}{lccc}
\hline & Control & $\mathrm{CH}$ & $\mathrm{CH}+\mathrm{NO}$ \\
\hline Body weight $\mathrm{g}$ & $410 \pm 4$ & $276 \pm 7^{*}$ & $273 \pm 4^{*}$ \\
Cardiac index $\mathrm{mL} \cdot \mathrm{min}^{-1} \cdot \mathrm{kg}$ & $167 \pm 11$ & $177 \pm 14$ & $183 \pm 13$ \\
PA pressure $\mathrm{mmHg}$ & $15 \pm 1$ & $27 \pm 1^{*}$ & $29 \pm 1^{*}$ \\
Aortic pressure $\mathrm{mmHg}$ & $115 \pm 4$ & $96 \pm 6^{*}$ & $94 \pm 5^{*}$ \\
TPRI $\mathrm{mmHg} / \mathrm{mL}^{-1} \cdot \mathrm{min} \cdot \mathrm{g}^{-1}$ & $87 \pm 3$ & $157 \pm 7^{*}$ & $158 \pm 5^{*}$ \\
$\mathrm{SVRI} \mathrm{mmHg} / \mathrm{mL}^{-1} \cdot \mathrm{min} \cdot \mathrm{g}^{-1}$ & $700 \pm 49$ & $554 \pm 39$ & $528 \pm 48$ \\
$\mathrm{RV} / \mathrm{LV}+\mathrm{S}$ & $0.26 \pm 0.01$ & $0.43 \pm 0.01^{*}$ & $0.44 \pm 0.01^{*}$
\end{tabular}

$\mathrm{CH}$ : chronic hypoxia; NO: chronic nitric oxide infusion; PA: pulmonary artery; TPRI: total pulmonary resistance index; SVRI: systemic vascular resistance index; $\mathrm{RV} / \mathrm{LV}+\mathrm{S}$ : right ventricular plus septal weight. $*$ : $\mathrm{p}<0.05$ vs control. Other differences between the groups are not significant.

and probably related to the significant elevation in methaemoglobin fraction (table 2).

Baseline perfusion pressure in the isolated lungs was equally elevated in the groups $\mathrm{CH}(7.1 \pm 0.3 \mathrm{mmHg})$ and $\mathrm{CH}+\mathrm{NO}(7.0 \pm 0.4 \mathrm{mmHg})$ compared to normotensive controls $(6.0 \pm 0.2 \mathrm{mmHg} ; \mathrm{p}<0.05)$. In addition, the $P / Q^{\prime}$ relationship was shifted toward higher pressures in isolated lungs of chronic hypoxic rats compared to normoxic controls (fig. 2). In hypoxic rats, no significant difference in $P / Q^{\prime}$ relationships was noted between rats that did and did not receive the NO infusion (fig. 2).

The distensibility model analysis of the $P / Q^{\prime}$ data $[14$, 20] yielded a good fit to the data in all lungs (fig. 2). The parameter $R$ o (interpreted as vascular resistance at near-zero pressure) was significantly increased by chronic hypoxia (table 3 ). There were no other statistically significant differences in the $P / Q^{\prime}$ parameters between the groups, although $\alpha$ (interpreted as distensibility of resistance vessels) tended to be higher in the $\mathrm{CH}$ than in other groups, and there was a tendency for $R$ o to be reduced by NO infusion (table 3 ).

To test the possibility that the pulmonary hypertension was not reduced by chronic NO infusion because NO was inactivated by haemoglobin in the blood before reaching the pulmonary vasculature, an additional experiment was performed in isolated, blood-perfused lungs of normal, control rats. Vasoconstrictor responses to repeated hypoxic challenges were unaffected by the infusion $(2.5$ $\left.\mu \mathrm{L} \cdot \mathrm{h}^{-1}\right)$ of saturated NO solution into the inflow cannula. For example, the increase in perfusion pressure elicited by the sixth hypoxic challenge after starting the infusion was $24.7 \pm 12.5 \mathrm{mmHg}$, compared to $25.5 \pm 7.0 \mathrm{mmHg}$ in lungs where only the solvent (deoxygenated saline) was infused.

Table 2. - Haematological data

\begin{tabular}{lccc}
\hline & Control & $\mathrm{CH}$ & $\mathrm{CH}+\mathrm{NO}$ \\
\hline Haematocrit \% & $41 \pm 1$ & $71 \pm 1^{*}$ & $70 \pm 1^{*}$ \\
Total haemoglobin $\mathrm{g} \cdot \mathrm{dL} \mathrm{L}^{-1}$ & $14.2 \pm 0.2$ & $23.6 \pm 0.3^{*}$ & $27.1 \pm 1.2^{* \dagger}$ \\
Methaemoglobin \% & $\mathrm{NM}$ & $1.5 \pm 0.2$ & $20.4 \pm 3.2^{\dagger}$ \\
\hline
\end{tabular}

$\mathrm{CH}$ : chronic hypoxia; NO: chronic nitric oxide infusion; NM: not measured. *: $\mathrm{p}<0.05$ vs control; ${ }^{\dagger}: \mathrm{p}<0.05$ vs $\mathrm{CH}$. Other differences between the groups are not significant. 

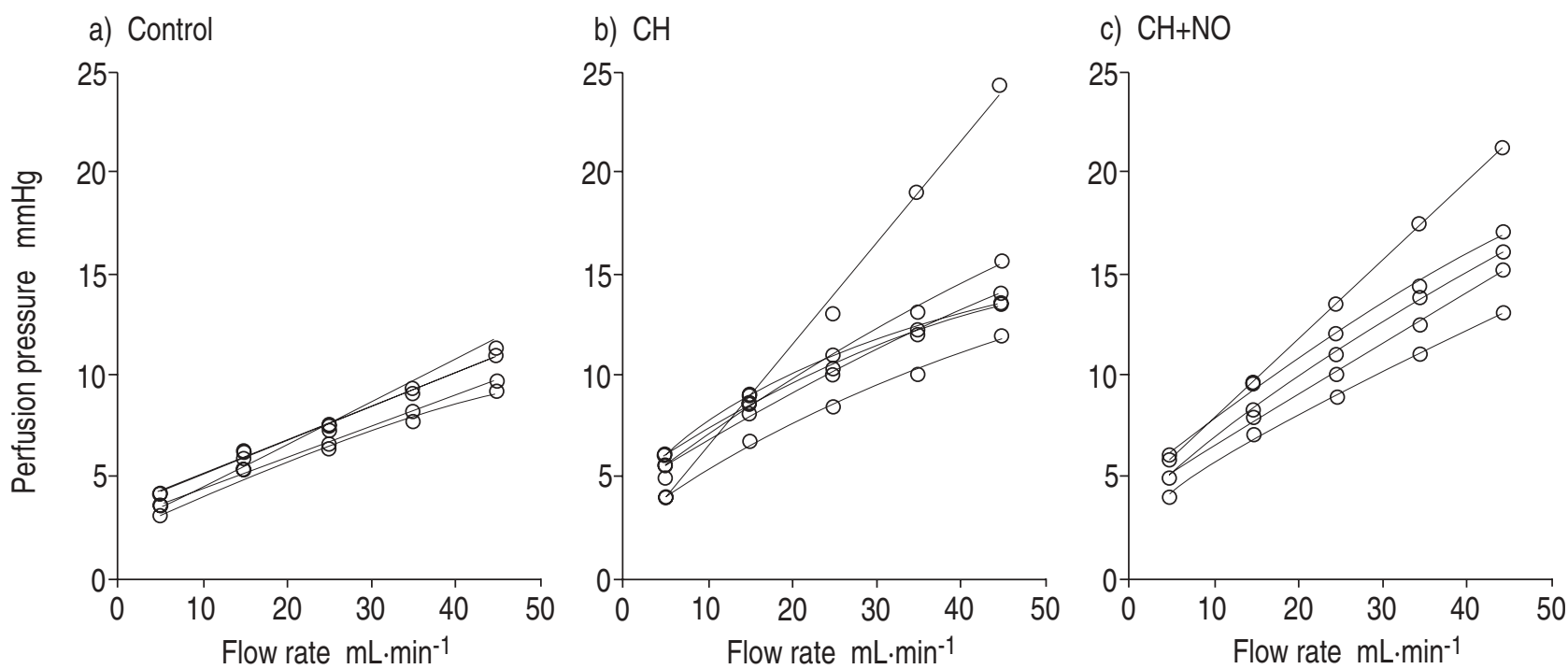

Fig. 2. - The vascular pressure-flow curves in isolated perfused rat lungs: a) control; b) $\mathrm{CH}$; c) $\mathrm{CH}+\mathrm{NO}$. Individual data points are shown along with the best fits to the nonlinear distensibility model [14]. $\mathrm{CH}$ : chronic hypoxia; NO: chronic nitric oxide infusion. The mean pressure-flow curves are shifted towards higher pressures in the chronically hypoxic groups $(\mathrm{CH}$ and $\mathrm{CH}+\mathrm{NO})$ as compared to controls ( $<<0.05)$; whereas, the difference between the $\mathrm{CH}$ and $\mathrm{CH}+\mathrm{NO}$ groups is not significant (repeated measures analysis of variance).

Table 3. - Results of the pulmonary vascular pressureflow data nonlinear evaluation

\begin{tabular}{llll}
\hline & Control & \multicolumn{1}{c}{$\mathrm{CH}$} & $\mathrm{CH}+\mathrm{NO}$ \\
\hline$R \mathrm{o} \mathrm{mmHg} \cdot \mathrm{mL}^{-1} \cdot \mathrm{min}$ & $0.20 \pm 0.02$ & $0.70 \pm 0.22^{*}$ & $0.38 \pm 0.04$ \\
$\alpha \% \cdot \mathrm{mHgg}^{-1}$ & $0.64 \pm 0.48$ & $2.79 \pm 1.13$ & $0.83 \pm 0.34$ \\
$P_{\mathrm{v}} \mathrm{mmHg}$ & $2.74 \pm 0.25$ & $3.38 \pm 0.46$ & $3.54 \pm 0.31$ \\
\hline
\end{tabular}

$\mathrm{CH}$ : chronic hypoxia; NO: chronic nitric oxide infusion. $R$ o, $\alpha$ and $P_{\mathrm{v}}$ are the parameters of the nonlinear equation describing the pulmonary vascular pressure-flow data [14]. Ro is interpreted as vascular resistance at near-zero pressure, $\alpha$ as vascular distensibility, and $P_{\mathrm{v}}$ as the model-optimized effective outflow pressure. *: $\mathrm{p}<0.05$ vs control. Other differences between the groups are not significant.

\section{Discussion}

The aim of this study was to test the long-term infusion of saturated NO solution as a possible treatment for pulmonary hypertension. The technically difficult task of chronically infusing a substance as labile as NO was successfully accomplished, as indicated by enormous methaemoglobinaemia in the $\mathrm{CH}+\mathrm{NO}$ group. However, the technique did not prove effective in reducing pulmonary hypertension, despite the effectiveness of the chosen NO dose in isolated lungs perfused ex-vivo with a blood-free perfusate. Other means of NO delivery, such as inhalation of NO releasing compounds [21], should be sought for long-term use in chronic pulmonary hypertension.

Before starting the chronic study, we needed to test the ability of slow infusion of NO solution to dilate the pulmonary vascular bed because previous studies used either inhaled NO $[5-8,22]$ or bolus injections of NO solution $[2,23]$. Bolus injection of $1 \mu \mathrm{L}$ of saturated NO solution in Krebs' albumin perfused rat lungs has a quite minute vasodilator effect of $\sim 1 \mathrm{mmHg}$ [23]. The effectiveness of infusing the same amount over $24 \mathrm{~min}$ (corresponding to $2.5 \mu \mathrm{L} \cdot \mathrm{h}^{-1}$ used in this study) was unknown. The results show that the inhibition of vasoconstrictor reactivity during this regimen of $\mathrm{NO}$ infusion was surprisingly marked in this haemoglobin-free preparation (fig. 1). This corresponds to reports of the remarkable vasodilator effectiveness of inhaled NO, which reduces pulmonary hypertension at doses $<40 \mathrm{ppm}$ [5-8, 22].

RimAR and GiLlis [13] showed that adding blood to the blood-free perfusate of isolated lungs abolished the vasodilator effectiveness of the lung effluent during NO inhalation, documenting that the pulmonary selectivity of the $\mathrm{NO}$ vasodilation is due to rapid NO inactivation by haemoglobin. Based on their work, it was expected that the effectiveness of NO infused in vivo would be less than in the isolated lung perfused with blood-free medium. To minimize this influence, the tip of the infusing cannula was advanced close to the right atrium, so that the travel time of NO from the cannula to the pulmonary arteries was of the order of a few hundred milliseconds. It was assumed this time might be sufficient for most of the infused NO to reach the pulmonary arteries. Nevertheless, the additional experiment with blood-perfused isolated lungs indicates that the inactivation of NO by haemoglobin is much faster than anticipated and explains the failure of infused NO to reduce pulmonary hypertension.

The pulmonary vascular resistive properties are most completely described by the $P / Q^{\prime}$ relationship. The pressure flow data correspond to in situ haemodynamic measurements in that the $P / Q^{\prime}$ curves were shifted towards higher pressures in chronic hypoxia, but they were not moved back towards control by chronic NO infusion.

Interpretation of the pulmonary vascular $P / Q^{\prime}$ relationship is complicated and not entirely clear. Traditionally, the $P / Q^{\prime}$ data have been interpreted in terms of the ohmic Starling resistor model of the pulmonary circulation [24]. In this linear model, the flow through each of the parallel channels is determined by a critical closing pressure and a constant ohmic resistance (independent of flow and pressure). The shortcomings of this concept were discussed in detail recently $[14,25]$. One obvious simplification is the independence of ohmic resistance on 
intravascular pressure, which apparently contradicts the fact that all pulmonary vessels are very thin-walled and distensible [26].

An alternative approach to explain the shape of the $P / Q^{\prime}$ curves, originating from the work of ZHUANG et al. [27], takes vascular distensibility into account. In this model, the $P / Q^{\prime}$ nonlinearity is acknowledged and explained by the decrease in resistance caused by vessel distension with rising flow (and thus also pressure), resulting in a smaller increase in pressure with each subsequent rise in flow. Recently, a relatively simple version of a distensible vessel model was introduced by LINEHAN et al. [14]. Practical implementation of this method includes nonlinear regression of the $P / Q^{\prime}$ data, dealing with only two or three parameters (depending on whether $P_{\mathrm{v}}$ is treated as input data or as a parameter). $R_{\mathrm{o}}$ can be interpreted as representing pulmonary vascular resistance when the vessels are in a nondistended state (intravascular pressure approaches zero). The parameter $\alpha$ represents the vascular distensibility. As argued by LiNEHAN et al. [14], the close fit of the model to the actual data suggests that $\alpha$ corresponds mainly to the distensibility of the vessels that contribute most to the vascular resistance [14]. The model was developed and validated in isolated dog lobes under control conditions [14], and was later applied to characterize acute hypoxic vasoconstriction in isolated lungs of neonatal piglets [20]. The present study is the first to utilize this method in pulmonary hypertension and in the rat.

The results show a marked increase in $R_{0}$ in chronic hypoxia (table 3 ), which can be viewed as reflecting the reduced diameter of resistance vessels in an unstretched state. This corresponds well with vasoconstriction and smooth muscle proliferation in the wall of small pulmonary arteries during chronic hypoxia [26], and is consistent with marked pulmonary hypertension in the $\mathrm{CH}$ group. The differences between the groups in the $P / Q^{\prime}$ data and analysis parameters do not result from difference in size of the animals, as the results were similar in the supplemental experiment with three control and three $\mathrm{CH}$ lungs, in which flow was normalized to the dry lung weight (fig. 3). This reflects the previously described observation that the overall body growth is retarded in chronic hypoxia while the lung growth is not, resulting in larger lung weights relative to body weight in chronically hypoxic than in normoxic rats [28].

Vascular distensibility, $\alpha$ showed a tendency towards an increase in chronic hypoxia, although the difference in $\alpha$ between the $\mathrm{CH}$ and control groups did not reach statistical significance $(p=0.08)$. This tendency may reflect the relatively low ability of just five flow values to uniquely resolve three parameters. In fact, when this possibility was tested in three control and three $\mathrm{CH}$ lungs with 12 flow values in the range of $3-45 \mathrm{~mL} \cdot \mathrm{min}^{-1}$, the results were qualitatively similar ( $R$ o markedly increased in $\mathrm{CH}$, no significant differences in $\alpha$ and $P_{\mathrm{v}}$ ), but the values of $\alpha$ were very similar between control and $\mathrm{CH}$ lungs (fig. 3).

There is another potential methodological limitation of this study. The distensible model was originally developed for pulmonary outflow pressure exceeding alveolar pressure (zone 3) [14]. In the present experiments, the end of the outflow cannula was below the level of the lung, ensuring slightly negative outflow pressure,

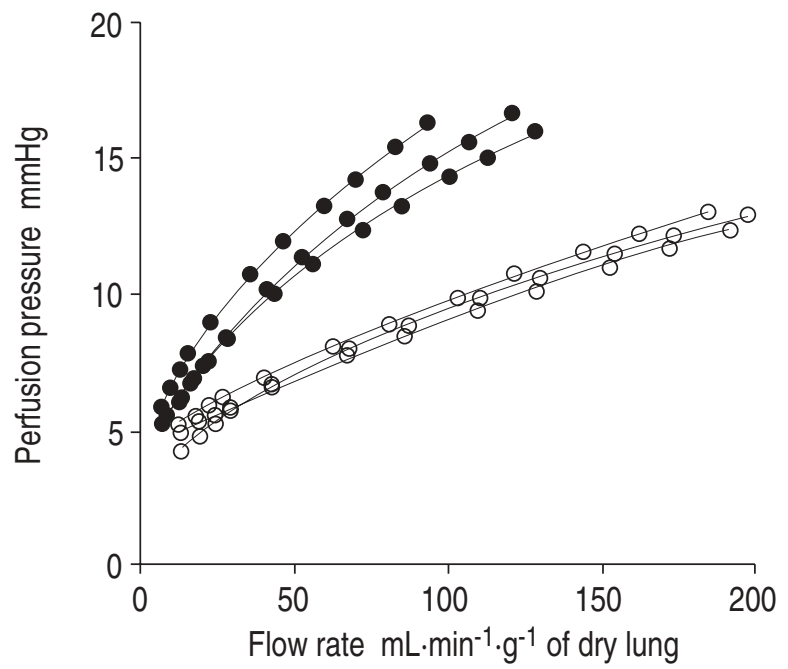

Fig. 3. - The pulmonary vascular pressure-flow curves in a supplemental experiment under the zone 3 conditions. The lungs were perfused with Krebs' albumin solution as described in the "Methods" section except for the outflow pressure which was set at $+7 \mathrm{cmH}_{2} \mathrm{O}$ $(5.1 \mathrm{mmHg})$. In addition, the lung ventilation was suspended at endexpiration for the duration of the pressure-flow measurement. Individual data points from three control and three chronically hypoxic isolated rat lungs are shown along with the best fits to the nonlinear distensibility model [14]. The flow rate is normalized to lung dry weight (the results were similar for the raw data). The mean model-optimized parameters in control and chronically hypoxic lungs were, respectively, 0.13 and $0.42 \mathrm{mmHg} / \mathrm{ml} / \mathrm{min} / \mathrm{g}$ of dry lung for $R_{\mathrm{o}}(\mathrm{p}<0.005), 3.3$ and $3.8 \% / \mathrm{mmHg}$ for $\alpha(\mathrm{NS})$, and 4.0 and 4.1 for $P_{\mathrm{v}}(\mathrm{NS}) . \longrightarrow$ : chronic hypoxia; - - - : control.

while alveolar pressure never dropped below zero (zone 2 ). The flow through the lung is determined by the difference between the pressures at the inflow and outflow and the vascular resistance between these two points. In zone 3, the outflow point is the actual end of the pulmonary circulation. Because of the collapsibility of the pulmonary veins, the effective outflow pressure in zone 2 is the pressure surrounding the collapsible vascular segment, i.e. the alveolar pressure [24]. Thus, the parameter $P_{\mathrm{v}}$ was referred to as effective outflow pressure rather than venous pressure. However, as the lungs were continuously ventilated during the $P / Q^{\prime}$ measurement, the alveolar pressure oscillated between 2.5 and $9 \mathrm{cmH}_{2} \mathrm{O}$, and the effects on the transmural pressure of the small pulmonary vessels cannot be accurately predicted. $P_{\mathrm{V}}$ reflects a central tendency of alveolar pressure, but a simple mean may not be mathematically appropriate due to the nonlinearity of the model. Also, whether the changes in lung volume have any effect on the model is unknown. Nevertheless, qualitatively identical results were observed in a supplemental experiment with three $\mathrm{CH}$ and three control lungs perfused in zone 3 (outflow pressure $7 \mathrm{cmH}_{2} \mathrm{O}$ ) and ventilation suspended at endexpiration (fig. 3), supporting the conclusions of this study regarding the effect of chronic hypoxia on the pulmonary vascular pressure-flow relationship and its interpretation using the nonlinear distensible model.

Acknowledgements: The authors thank C.A. Dawson for valuable advice regarding the implementation of the distensible model in their laboratory. 


\section{References}

1. Salvaterra CG, Rubin LJ. Investigation and management of pulmonary hypertension in chronic obstructive pulmonary disease. Am Rev Respir Dis 1993; 148: 14141417.

2. Archer SL, Rist K, Nelson DP, DeMaster EG, Cowan $\mathrm{N}$, Weir EK. Comparison of the hemodynamic effects of nitric oxide and endothelium-dependent vasodilators in intact lungs. J Appl Physiol 1990; 68: 735-747.

3. Pepke-Zaba J, Higenbottam T, Dinh-Xuan AT, Stone D, Wallwork J. Inhaled nitric oxide as a cause of selective pulmonary vasodilation in pulmonary hypertension. Lancet 1991; 338: 1173-1174

4. Frostell CG, Blomqvist H, Hedenstierna G, Lundberg J, Zapol WM. Inhaled nitric oxide selectively reverses human hypoxic pulmonary vasoconstriction without causing systemic vasodilation. Anesthesiology 1993; 78: 427435 .

5. Gerlach H, Rossaint R, Pappert D, Falke KJ. Timecourse and dose-response of nitric oxide inhalation for systemic oxygenation and pulmonary hypertension in patients with adult respiratory distress syndrome. Eur $J$ Clin Invest 1993; 23: 499-502.

6. Roberts JD, Lang P, Bigatello L, Vlahakes GJ, Zapol WM. Inhaled nitric oxide in congenital heart disease. Circulation 1993; 87: 447-453.

7. Rossaint R, Falke KJ, Lopez F, Slama K, Pison U, Zapol WM. Inhaled nitric oxide for the adult respiratory distress syndrome. $N$ Engl J Med 1993; 328: 399-405.

8. Journois D, Pouard P, Mauriat P, Malhére T, Vouhé P, Safran D. Inhaled nitric oxide as a therapy for pulmonary hypertension after operations for congenital heart defects. J Thorac Cardiovasc Surg 1994; 107: 1129-1135.

9. Kouyoumdjian C, Adnot S, Levame M, Eddahibi S, Bousbaa H, Raffestin B. Continuous inhalation of nitric oxide protects against development of pulmonary hypertension in chronically hypoxic rats. J Clin Invest 1994; 94: $578-584$.

10. Roberts JD, Roberts CT, Jones RC, Zapol WM, Bloch KD. Continuous nitric oxide inhalation reduces pulmonary arterial structural changes, right ventricular hypertrophy, and growth retardation in the hypoxic newborn rat. Circ Res 1995; 76: 215-222.

11. Laidler KJ. Chemical Kinetics. 3rd edn. New York, Harper and Row, 1987; pp. 147-150.

12. Stavert DM, Lehnert BE. Nitrogen oxide and nitrogen dioxide as inducers of acute pulmonary injury when inhaled at relatively high concentrations for brief periods. Inhal Toxicol 1990; 2: 53-67.

13. Rimar S, Gillis CN. Selective pulmonary vasodilation by inhaled nitric oxide is due to hemoglobin inactivation. Circulation 1993; 88: 2884-2887.

14. Linehan JH, Haworth ST, Nelin LD, Krenz GS, Dawson CA. A simple distensible vessel model for interpreting pulmonary vascular pressure-flow curves. J Appl Physiol 1992; 73: 987-994.

15. McMurtry IF. Angiotensin is not required for hypoxic constriction in salt solution-perfused rat lungs. $J$ Appl Physiol: Respirat Environ Exercise Physiol 1984; 56: 375-380.

16. Hauge A. Conditions governing the pressor response to ventilation hypoxia in isolated perfused rat lungs. Acta Physiol Scand 1968; 72: 33-44.

17. Archer SL, Hampl V, Nelson D, Sidney E, Peterson DA, Weir EK. Dithionite increases radical formation and decreases vasoconstriction in the lung: evidence that dithionite does not mimic alveolar hypoxia. Circ Res 1995; 77: 174-181.

18. Archer SL, Shultz PJ, Warren JB, Hampl V, DeMaster EG. Preparation of standards and measurement of nitric oxide, nitroxyl, and related oxidation products. Methods: A Companion to Methods in Enzymology 1995; 7: 21-34.

19. Hampl V, Archer SL, Nelson DP, Weir EK. Chronic EDRF inhibition and hypoxia: effects on pulmonary circulation and systemic blood pressure. J Appl Physiol 1993; 75: 1748-1757.

20. Nelin LD, Krenz GS, Rickaby DA, Linehan JH, Dawson CA. A distensible vessel model applied to hypoxic pulmonary vasoconstriction in the neonatal pig. J Appl Physiol 1993; 74: 2049-2056.

21. Hampl V, Tristani-Firouzi M, Hutsell TC, Archer SL. Nebulized nitric oxide/nucleophile adduct reduces chronic pulmonary hypertension. Cardiovasc Res 1996; 31: $55-62$.

22. Kinsella JP, McQueston JA, Rosenberg AA, Abman SH. Hemodynamic effects of exogenous nitric oxide in ovine transitional pulmonary circulation. Am J Physiol 1992; 263: H875-H880.

23. Isaacson TC, Hampl V, Weir EK, Nelson DP, Archer SL. Increased endothelium-derived nitric oxide in hypertensive pulmonary circulation of chronically hypoxic rats. J Appl Physiol 1994; 76: 933-940.

24. Permutt S, Riley RL. Hemodynamics of collapsible vessels with tone: the vascular waterfall. J Appl Physiol 1963; 18: 924-932.

25. Mitzner W, Huang I. Interpretation of pressure-flow curves in the pulmonary vascular bed. In: Will JA, Dawson CAW, Weir EK, Buckner CK, eds. The Pulmonary Circulation in Health and Disease. Orlando, Academic Press, 1987; pp. 215-230.

26. Reid LM. Structural remodeling of the pulmonary vasculature by environmental change and disease. In: Wagner WW, Weir EK, eds. The Pulmonary Circulation and Gas Exchange. Armonk, Futura, 1994; pp. 77-110.

27. Zhuang FY, Fung YC, Yen RT. Analysis of blood flow in cat's lung with detailed anatomical and elasticity data. J Appl Physiol 1983; 55: 1341-1348.

28. Hunter C, Barer GR, Shaw JW, Clegg EJ. Growth of the heart and lungs in hypoxic rodents: a model of human hypoxic disease. Clin Sci Mol Med 1974; 46: 375-391. 